\title{
Assessment of Environmental Impact of Manufacturing Steel Considering Physical Damage to Human Health*1
}

\author{
Norihiro Itsubo*2 and Atsushi Inaba \\ National Institute for Advanced Industrial Science and Technology (AIST), 305-8569, 16-1 Onogawa, Tsukuba, Ibaraki, Japan
}

Weighting in LCIA (life cycle impact assessment) can be classified into two types; midpoint and endpoint. To improve the transparency and reliability of impact assessment, the development of the endpoint approach has been required internationally in recent years. A methodology that enables the assessment of physical damage for Japanese products has to be developed, because the actual damage is dependent on the emission area and exposed area. Regarding LCIA for materials, though some studies have already been performed, there is no consensus among the results of various methods because of the lack of reliability and transparency in conventional methodologies. This paper describes the results of a case study for steel sheets applying the Japanese endpoint-type LCIA method. We adopted the DALY concept to indicate the damage to human health. It is found that the subjective judgments can be reduced maximally by applying the endpoint approach.

(Received September 2, 2002; Accepted November 15, 2002)

Keywords: life cycle assessment, damage functions, life cycle impact assessment, human health, DALY: disability-adjusted life year

\section{Introduction}

LCA (life cycle assessment) has been recognized as a useful quantitative assessment tool for constructing an environmental management system for the industry. LCIA (life cycle impact assessment) that estimates potential environmental impact throughout a product's life cycle is one of the essential elements of LCA. In Japan, research studies including the weighting across impact categories have attracted the attention of LCA practitioners, because the results of weighting contribute to the facilitation of decision making.

Subjective judgment has to be involved in weighting. The problem is how to treat subjectivity in the case of LCIA. At present, LCIA approaches which include weighting can be classified into two types; midpoint and endpoint. The former concentrates on the comparison between the potential effects of environmental problems such as incremental radiative forcing and proton release. This approach does not take the kind of receptor and the severity of each impact into account, although this information is essential in order to consider weighting. In contrast to the midpoint-type approach, the endpoint-type approach focuses on the actual damage of receptors due to the emission of substances. This approach is now focused on internationally, and enables us to solve the above problem in the use of the conventional methodologies. As environmental impacts are quite independent of the emission area, we cannot apply the European methodology directly in LCIA for Japanese products.

The impact assessment committee of the LCA National Project of Japan has started developing an impact assessment program based on the endpoint approach considering the environmental conditions of Japan. Thus far, we have already developed several damage functions related to human health such as marginal increase in thermal stress and incidence of

\footnotetext{
${ }^{* 1}$ This paper was partially published in J. Japan Inst. Metals 66 (2002) 499-505.

*2 Tel: +81-298-61-8110, Fax: +81-298-61-8110,

E-mail: itsubo-n@aist.go.jp
}

malaria due to the emission of carbon dioxide, which are the components of this program. This damage of category endpoints can be integrated reasonably with the application of years of damage indicators such as the loss of life expectancy.

Regarding the assessment for metals, the authors have published the results of LCIA comparing the results of weighting for some metals except for the discussions related to endpoint approaches. ${ }^{1)}$ It was difficult for us to provide reasonable information based on the midpoint approach, because the results of LCIA by these conventional methods were completely independent of the applied methodologies. There are few studies relating the LCIA for metals based on the endpoint approaches. In order to validate the effectiveness of the endpoint approach, we conducted a case study for manufacturing steel sheets in this study.

\section{Endpoint Approach and Damage Functions}

Figure 1 illustrates the differences between midpoint approach and endpoint approach. According to ISO14042, ${ }^{2)}$ in order to perform characterization of LCIA, a characterization factor has to be chosen for every impact category. In general, characterization factors relate LCI with category midpoints such as infrared radiative forcing and proton release without considering category endpoints like the loss of biodiversity. ${ }^{2}$ These indicators for the midpoint level are useful in evaluating the potential impacts of a corresponding impact category. However, the information concerning midpoints is not sufficient for weighting across impact categories, because they do not provide any information concerning receptors and the quantified damage to them. At present, the interests of research towards the development of LCIA methodology are shifting from the midpoint to the endpoint approach. Internationally well-known methodologies such as Eco-indicator 99, ${ }^{3)}$ EPS, ${ }^{4)}$ and ExternE ${ }^{5)}$ adopt the endpoint-type approach taking potential damage of endpoints into account. In Japan, however, all the methods proposed previously concentrated on the comparison between the results of characterization or normalization 


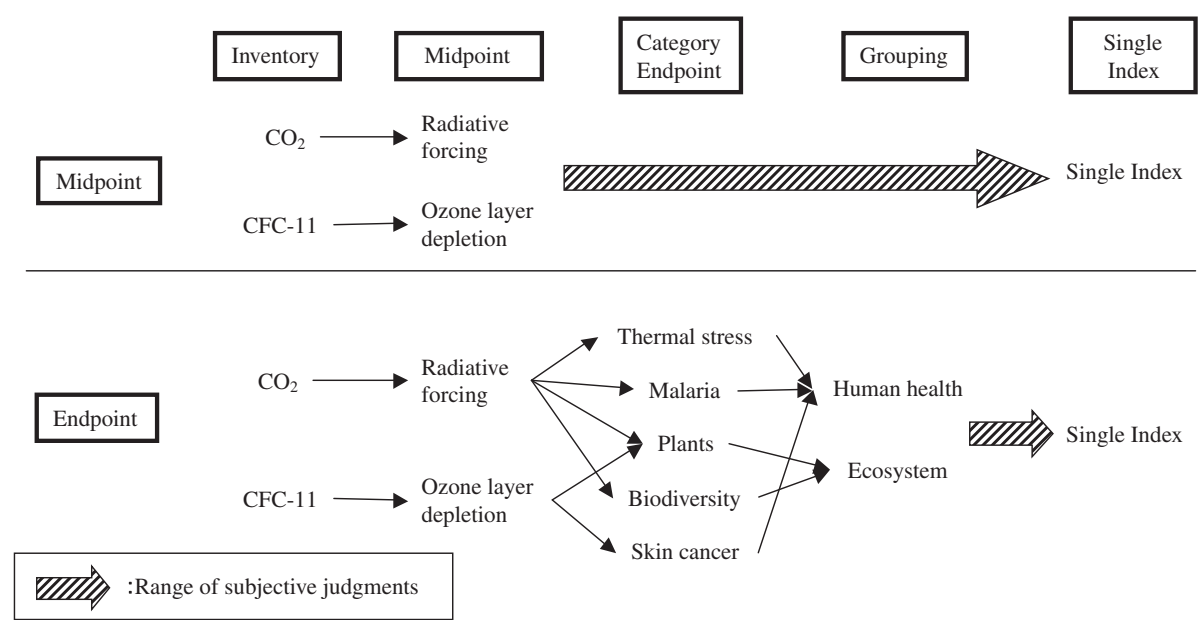

Fig. 1 Comparison of characteristics between midpoint approach and endpoint approach in LCIA.

expressed in midpoint levels. ${ }^{6,7)}$

The impact assessment committee in LCA National Project of Japan has started developing the impact assessment program based on the damage of the endpoint level. ${ }^{8)}$ This system will provide not only a single index by weighting but also potential damage of safeguard subjects to meet various practitioners' aims. ${ }^{9}$

\section{Indicator of the damage assessment for human health}

There are various endpoints to be considered in damage assessment of LCIA. Table 1 compares the types of endpoints and the indicator expressing the amount of damage taken into account in several LCIA programs. In general, all methodologies estimate the damage to human health and biodiversity. The types of damage indicators applied are independent of the LCIA programs except in the case of human health. In principal, all of the LCIA methodologies listed in Table 1 count the loss of life expectancy as a damage indicator for human health. DALY (Disability Adjusted Life Year) adopted in Eco indicator 99 and AIST/LCA project of Japan ${ }^{10)}$ indicates the additional loss of life years by death and disease, whereas YOLL (Years Of Life Lost) adopted in EPS takes only death into account. In order to compare the calculated results of LCIA for metals across the LCIA methodologies, we chose human health in this study. Detailed information on DALY is described by Murray. ${ }^{11,12)}$

\section{Case Study Applying Damage Functions}

We describe the results of a case study for manufacturing steels (stainless steel sheet and carbon steel sheet) applying damage functions related with human health. The modeled life cycle steps of the system include mining the raw materials, oversea transportation, refining and processing with heat treatment. The manufacture of steel essentially involves two stages: the production of molten pig iron in a blast furnace and transformation of the pig iron in a topblown basic oxygen converter. An electric furnace is assumed to be applied to the production of stainless steel. Transportation that connects every phase is also included. Domestic transportations are assumed to use diesel trucks with a 10-ton carrying capacity. For overseas transportation, we estimated the emissions considering the distances of the

Table 1 Endpoints (upper column of each cell) and the damage factors (bottom column of each cell) considered in various endpoint methodologies of LCIA.

\begin{tabular}{|c|c|c|c|}
\hline & EPS ver. $2000^{3)}$ & Eco-indicator'992) & AIST/LCA pro. ${ }^{7-9)}$ \\
\hline \multirow{4}{*}{ Human life } & Human health & Human health & Human health \\
\hline & $\begin{array}{l}\text { Death: YOLL, Others: the } \\
\text { number of diseases }\end{array}$ & DALY (death, disease) & DALY (death, disease) \\
\hline & Abiotic stock resources & Resource & Social welfare \\
\hline & $\mathrm{Kg}$ & MJ; Surplus energy & $\begin{array}{l}\text { Yen (resources, crops, fishery, } \\
\text { energy, timber) }\end{array}$ \\
\hline \multirow{4}{*}{ Ecosystem } & Biodiversity & Ecosystem quality & Biodiversity \\
\hline & $\begin{array}{l}\text { NEX (Normalized Extinction } \\
\text { of Species) }\end{array}$ & $\begin{array}{l}\text { PDF (Potentially Disappeared } \\
\text { Fraction) }\end{array}$ & $\begin{array}{l}\text { EINES (Expected Increase in } \\
\text { Number of Extinct Species) }\end{array}$ \\
\hline & Production capacity & & Primary productivity \\
\hline & $\begin{array}{l}\text { (crop, wood, fish and meat, soil } \\
\text { acidification, irrigation water, } \\
\text { drinking water) }\end{array}$ & & NPP (Net Primary Productivity) \\
\hline
\end{tabular}


Table 2 Inventory table for manufacturing $1 \mathrm{~kg}$ of stainless steel sheet and carbon steel sheet.

\begin{tabular}{lll}
\hline & Carbon steel sheet $(1 \mathrm{~kg})$ & Stainless steel sheet $(1 \mathrm{~kg})$ \\
\hline $\mathrm{CH}_{4}$ & $5.50 \times 10^{-6}$ & $1.71 \times 10^{-5}$ \\
$\mathrm{CO}_{2}$ & 1.98 & 4.14 \\
$\mathrm{~N}_{2} \mathrm{O}$ & $6.11 \times 10^{-5}$ & $3.86 \times 10^{-4}$ \\
$\mathrm{NO}_{x}$ & $1.00 \times 10^{-3}$ & $6.40 \times 10^{-3}$ \\
$\mathrm{SO}_{2}$ & $1.60 \times 10^{-3}$ & $1.03 \times 10^{-2}$ \\
$\mathrm{SPM}$ & $2.56 \times 10^{-5}$ & $1.10 \times 10^{-4}$ \\
$\mathrm{As}$ & $1.13 \times 10^{-9}$ & $3.53 \times 10^{-9}$ \\
$\mathrm{Cd}$ & $5.67 \times 10^{-11}$ & $1.76 \times 10^{-10}$ \\
$\mathrm{CO}$ & $3.11 \times 10^{-4}$ & $1.70 \times 10^{-3}$ \\
$\mathrm{Cr}$ & $1.13 \times 10^{-9}$ & $3.53 \times 10^{-9}$ \\
\hline
\end{tabular}

export countries and Japan for every resource. We used the LCA software to perform LCI, 'JEMAI-LCA ver. 1/NIRE ver. 3'. Table 2 shows the inventory table for ten substances related to both steel sheets. These substances affect human health through greenhouse effects and exposure to toxic substances.
Category endpoints involved in this study are acute death by thermal stress, malaria, dengue fever, respiratory disorder and cancer. The details relating the development of damage functions to these above category endpoints have been described in previous papers. ${ }^{13-15)}$ Figure 2 shows the causeeffect relationship considered in this case study. All of the damage functions used in this study are concerned with human health. Utilization of the damage functions enables us to obtain the information related to the marginal occurrence of death or disability for each type of health damage due to the release of pollutants. If we convert them into the loss of life expectancy, we can aggregate these various types of health damage into one common indicator. This index indicates the potential damage to human health caused by the production of steel sheet. We adopted DALY as an indicator of the damage to human health. The dimension of damage functions listed in Table 3 is DALY per $1 \mathrm{~kg}$ emission of pollutant. It is possible for us to assess the potential damage to human health caused by the production of steel sheets from the results obtained by multiplying the damage functions with the inventory data.

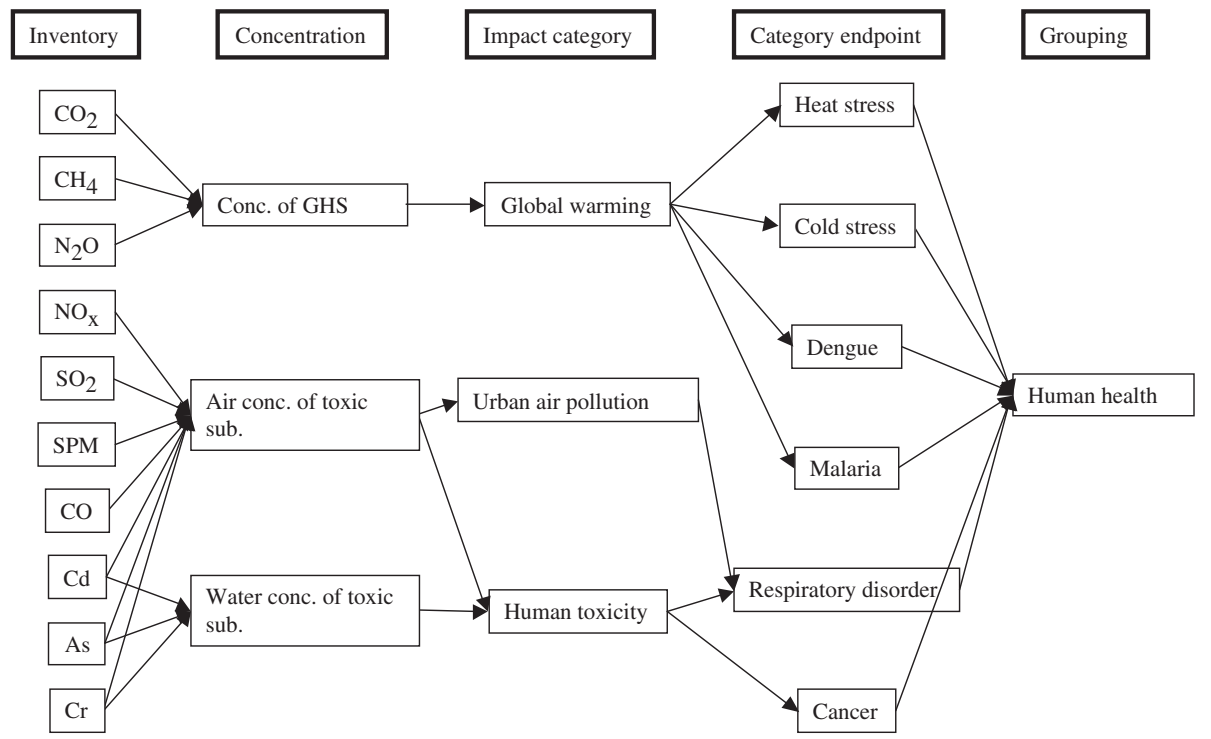

Fig. 2 Cause-effect chain considered in this study.

Table 3 Damage factors list considered in this study (unit: DALY/1 kg emission, GW: global warming, AP: urban air pollution, HT: human toxicity, HS: heat stress, CS: cold stress, MA: malaria, DF: dengue fever, RD: respiratory disorder, CN: cancer).

\begin{tabular}{|c|c|c|c|c|c|c|}
\hline Impact category & & & & & AP & HT \\
\hline Category endpoint & HS & $\mathrm{CS}$ & MA & DF & $\mathrm{RD}$ & $\mathrm{CN}$ \\
\hline $\mathrm{CH}_{4}$ & $1.5 \times 10^{-6}$ & $-2.9 \times 10^{-6}$ & $1.0 \times 10^{-5}$ & $3.1 \times 10^{-7}$ & & \\
\hline $\mathrm{CO}_{2}$ & $7.0 \times 10^{-8}$ & $-1.4 \times 10^{-7}$ & $5.0 \times 10^{-7}$ & $1.5 \times 10^{-8}$ & & \\
\hline $\mathrm{N}_{2} \mathrm{O}$ & $2.8 \times 10^{-4}$ & $-5.5 \times 10^{-4}$ & $2.0 \times 10^{-3}$ & $5.8 \times 10^{-5}$ & & \\
\hline $\mathrm{NO}_{\mathrm{x}}$ & & & & & $2.1 \times 10^{-4}$ & \\
\hline $\mathrm{SO}_{2}$ & & & & & $7.8 \times 10^{-5}$ & \\
\hline SPM & & & & & $7.7 \times 10^{-3}$ & \\
\hline NMVOC & & & & & $1.2 \times 10^{-6}$ & \\
\hline As & & & & & & $2.0 \times 10^{-1}$ \\
\hline $\mathrm{Cr}$ & & & & & & $9.8 \times 10^{-1}$ \\
\hline $\mathrm{CO}$ & & & & & $1.8 \times 10^{-5}$ & \\
\hline $\mathrm{Cd}$ & & & & & & $2.6 \times 10^{+1}$ \\
\hline
\end{tabular}


Figure 3 shows the aggregated potential damage to human health caused by the production of carbon steel sheet applying the damage functions to LCI. The result for a carbon steel sheet with cold rolling showed that the contribution of until the production of steel ingots was larger than those of hot rolling and cold rolling. Based on this result, we disaggregated the damage to human health caused by the production of steel ingots into several processes to detect the significant damage-causing processes. It was found that in the case of the production of steel ingot, the major impact on the environment was in the case of production of crude steel. Moreover, the production process of crude steel was also disaggregated into detailed processes. The production process of pig iron was the main contributor in the result for crude steel. The productions of cokes and coals were regarded as key processes, which had a considerable environmental impact in the production of carbon steel sheets. In order to improve the environmental impacts efficiently, it is recommended to concentrate on the reduction of the environmental impact of these processes.

Figure 4 shows the aggregated potential damage to human health in the case of stainless steel sheets. This figure shows that the environmental impact of the production process of stainless steel ingots was dominant. In contrast to the result for carbon steel sheets (Figure 3), the environmental impact for crude steel was not significant, and the impact in the case of manufacturing ferro-alloys were significant for the production of stainless steel ingots. The amounts of ferroalloys required to produce stainless steel ingots are close to that of crude iron (ferro-Ni: $0.29 \mathrm{~kg}$; ferro-Cr: $0.30 \mathrm{~kg}$; crude

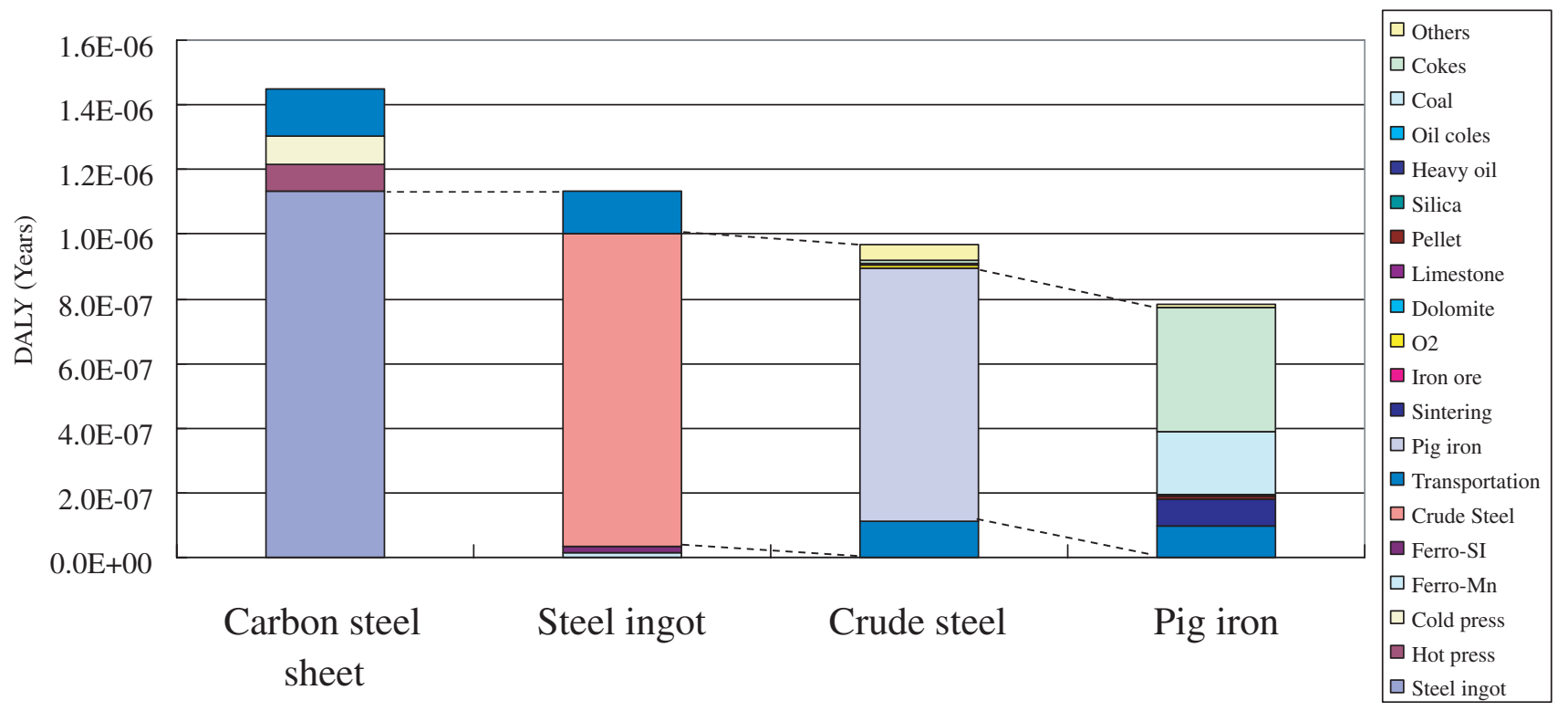

Fig. 3 Potential damage to human health in the production of carbon steel sheet. The processes having significant impacts were decomposed to identify the process with the maximum impact (unit of vertical line: DALY (years)).

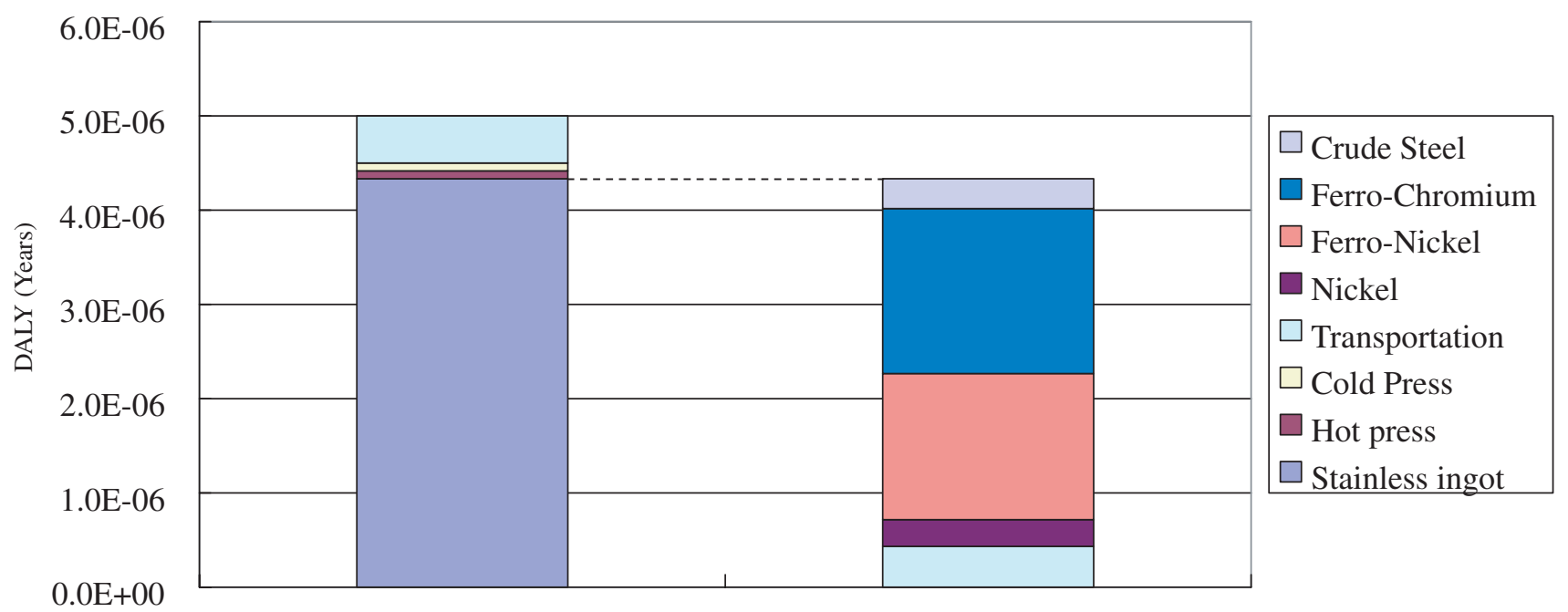

\section{Stainless steel sheet Stainless steel ingot}

Fig. 4 Potential damage to human health in the production of stainless steel sheet. The processes having significant impacts were decomposed to identify the process with the maximum impact (unit of vertical line: DALY (years)). 
iron: $0.31 \mathrm{~kg}$ (per $\mathrm{kg}$ stainless steel)). However, the fuels requirements to produce each raw material are different ((ferro-Ni: $1 \mathrm{~kg}$; Oil: $0.90 \mathrm{~kg}$; Coal: $0.65 \mathrm{~kg}$ ), (ferro-Cr: $1 \mathrm{~kg}$; Coal: $1.21 \mathrm{~kg}$ ), (crude steel $1 \mathrm{~kg}$ : Coal: $0.60 \mathrm{~kg}$ )). It was found that the large amount of fuel consumption in the production of ferro-alloys is the dominant factor in the environmental impacts caused by the production of steel ingots.

The compositions of pollutants for the damage to human health caused by the production of steel sheets are shown in Figure 5. The impact caused by the emission of carbon dioxide was the largest in both steel sheets. The impacts in the case of the emission of $\mathrm{NO}_{\mathrm{x}}, \mathrm{SPM}$ and $\mathrm{SO}_{2}$ followed. The damage by heavy metals is not significant as seen from this figure.

We compared the LCIA results of this study with the results obtained by other methodologies in Figure 6. Ecoindicator 99 and ExternE ${ }^{16)}$ focus on the physical damage to human health for the pollutants released in Europe. It can be noted that the components of the substance and the relationship between the steel sheets are similar among the methodologies.

However, the estimated values of total damage induced from the various methodologies differed within a factor of 3 . The main reasons for this difference are the differences in the area of consideration and the damage indicators adopted in each methodology. The result obtained from this study focuses on the damage emitted in Japan. The impacts concerning respiratory diseases caused by air pollutants are sensitive to the background of the emitted area. In addition, the exposure efficiency of air pollutants in Japan is higher

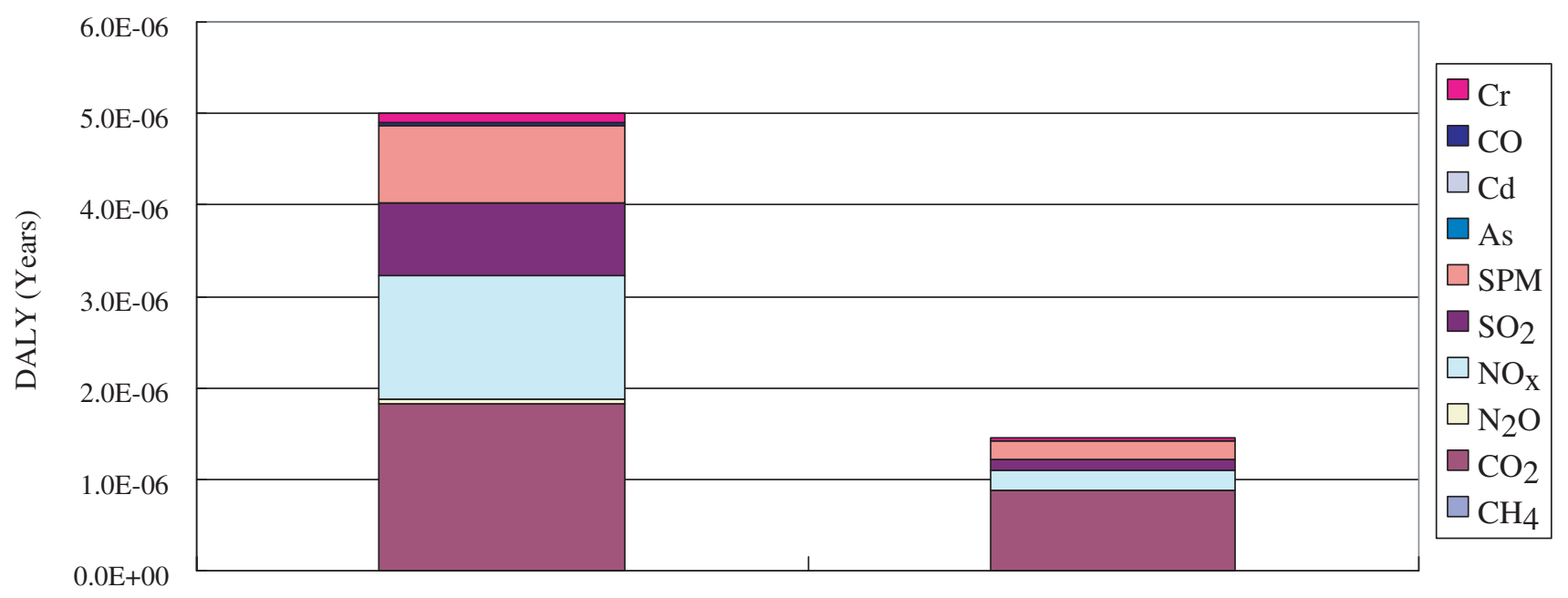

\section{Stainless steel sheet Carbon steel sheet}

Fig. 5 Contributions of pollutants to the damage to human health for the production of stainless steel sheet and carbon steel sheet (unit of vertical line: DALY (years)).

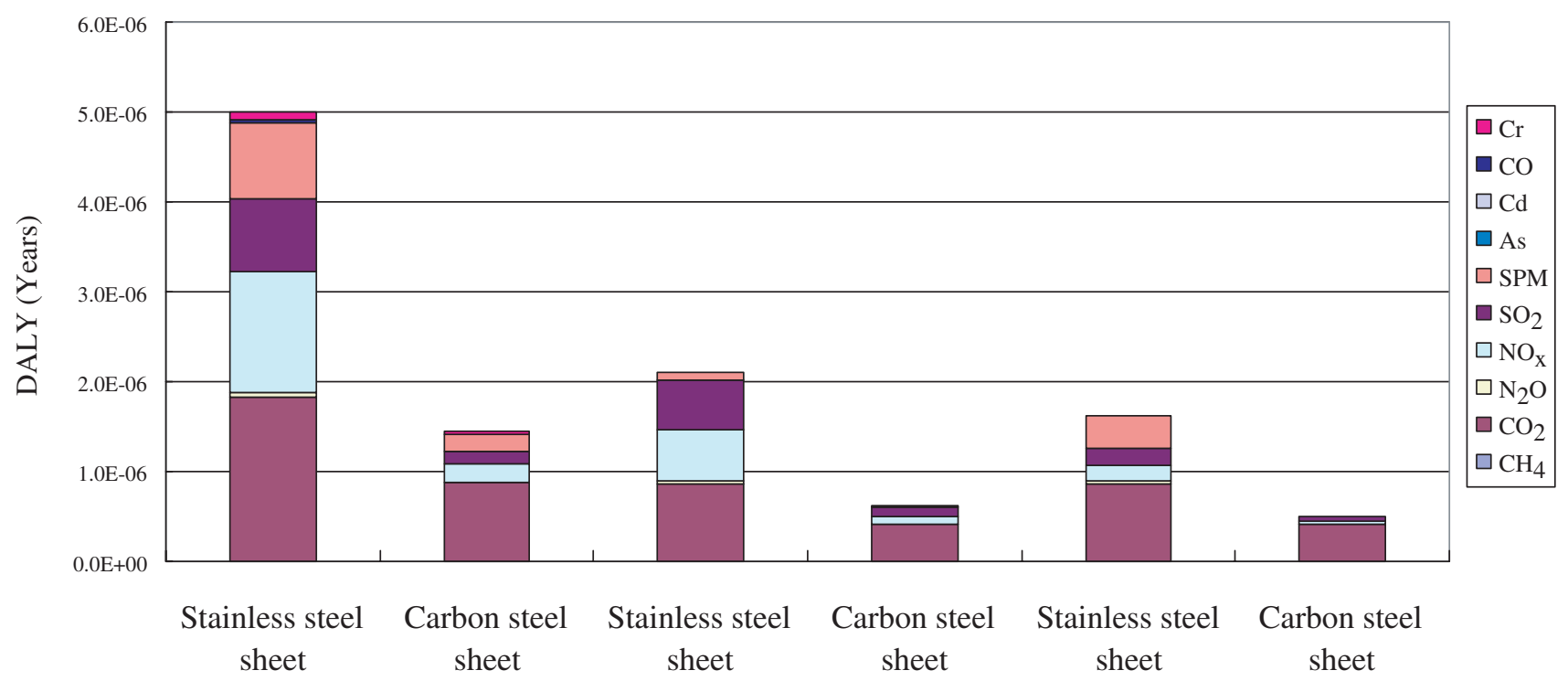

Fig. 6 Comparison of results between the methodologies of LCIA (left: this study, center: Ecoindicator'99 and right: ExternE (unit of vertical line: DALY (years)). 
than that in Europe, because the population densities of both places are quite different.

This study and Eco-indicator 99 adopted DALY for the indicator of human health, while ExternE uses YOLL. DALY incorporates the loss of life expectancy by death and disorder with consideration of the loss of quality of life. On the other hand, YOLL includes only death. This difference in the scope of health impact leads to the result calculated by ExternE being smaller in value than the results obtained by the other methodologies.

\section{Conclusions}

In Japan, weighting methodologies in LCIA which enable us to avoid a trade-off relationship have attracted the attention of LCA practitioners, and many methodologies have already been proposed at an international level. These methods compare the priorities between impact categories. It is impossible to obtain reasonable weighting factors from the integration between the midpoint levels. The development of endpoint-type methodologies taking state-of-the-art knowledge in the field of environmental science into account is required.

We adopted the DALY as an indicator of the damage to human health. This indicator has already been authorized by an international body such as WHO via discussions by an expert panel. Consequently, it is expected to maximally reduce subjective judgment and yield fair and adequate results based on the theory in medical statistics.

In this study, we described an application of several damage functions and integration into the level of endpoint taking steel sheets as examples. The key points in reducing the environmental impact effectively for a carbon steel sheet and stainless sheet were found to be different. For a carbon steel sheet, the contribution of carbon dioxide emitted from the production of coal and cokes was dominant. For a stainless steel sheet, the emissions of carbon dioxide, nitrogen oxide, sulfur dioxide, and particulate matter from the production of ferro-alloy were dominant. The results obtained by applying various endpoint methodologies were similar from the viewpoint of the components of substances. The difference in population density in the emission area is a key factor that affects the total amount of damage. The above results from this study cannot be obtained by the application of conventional LCIA methodologies. The significance of applying the endpoint approach in LCIA in material selection was proved through this study.

The total impact assessment system that treats the endpoint approach is now in the developmental stage. In the future, it will be necessary to construct damage functions for the entire category endpoints that are recognized as important. We focused on the assessment for the impact on human health. It is necessary to develop an LCIA methodology that provides comprehensive information relating various environmental impact based on sophisticated theory in natural science.

\section{Acknowledgements}

The authors would like to thank the New Energy and Industrial Technology Development Organization (NEDO) for their financial support.

\section{REFERENCES}

1) N. Itsubo, A. Inaba, Y. Matsuno, I. Yasui and R. Yamamoto: Current Status of Weighting Methodologies in Japan, Int. J. LCA 5 (1) (2000) $5-11$.

2) International Organization for Standardization: ISO14042, Environmental management — Life cycle assessment- Life cycle impact assessment (2000).

3) M. Goedkoop and R. Spriensma: The Eco-indicator 99, A damage oriented method for Life Cycle Impact Assessment, Methodology Report (1999).

4) B. Steen: A Systematic Approach to Environmental Priority Strategies in Product Development (EPS). Version 2000 Models and Data of the Default Method, Chalmers University of Technology (1999).

5) European Commission: ExternE, Externalities of Energy, vol. 7, Methodology 1998 update.

6) I. Yasui: A new Scheme of Life Cycle Impact Assessment Method Based on the Consumption on EcoBalance (1998) 89-92.

7) N. Itsubo and R. Yamamoto: Impact Assessment for Metals -A Comparative Study of Total Environmental Impacts Between Primary Metals and Secondary Metals_, JIE, 77, 11 (1998) 1080-1088.

8) A. Inaba, T. Mizuno and N. Itsubo: Development of Japanese LCIA Method Considering the Endpoint Damage, Proceedings of The Fourth International Conference on EcoBalance, (2000) 213-216.

9) N. Itsubo and A. Inaba: Definition of Safeguard Subjects for Damage Oriented Methodology in Japan, Proceedings of The Fourth International Conference on EcoBalance, (2000) 217-220.

10) N. Itsubo and A. Inaba: Development of Damage Functions for LCIA Based on Endpoint Damage, Proceedings of The Fourth International Conference on EcoBalance, (2000) 221-224.

11) C. Murray: Quantifying the Burden of Disease: the Technical Basis for Disability Adjusted Life Years, Bulletin of the World Health Organization 72 (3) (1994) 429-445.

12) C. Murray and A. Lopez (Eds.); The Global Burden of Disease, Volume 1, WHO/Harvard School of Public Health/World Bank, Harvard University Press, Boston 1996.

13) K. Itaoka, H. Uchida, N. Itsubo and A. Inaba: Life Cycle Impact Assessment of GHG Emission on Human Health, Proceedings of The Fourth International Conference on EcoBlance, (2000) p. 225-228.

14) K. Hayashi, N. Itsubo and A. Inaba: Damage Function of Stratospheric Ozone Depletion, Proceedings of The Fourth International Conference on EcoBalance, (2000) p. 237-240.

15) T. Fujii, Y. Nagata, N. Itsubo, T. Ohara and A. Inaba: Life Cycle Impact Assessment of Photochemical Oxidant through Damage Function Approach (Valuation of Damage Due to Ozone Concentration) Proceedings of The Fourth International Conference on EcoBalance, (2000) p. 241-244.

16) W. Krewitt, A. Trukenmüller, T. Bachmann and T. Heck: Countryspecific Damage Factors for Air Pollutants, Int. J. LCA 6 (4) (2001) 199-210. 